SPECIAL ISSUE ARTICLE

\title{
The endorsement of unity in diversity: The role of political orientation, education and justifying beliefs
}

\author{
Maykel Verkuyten*, Borja Martinovict, Anouk Smeekes $†$ \& Mathijs Kros $\dagger$ \\ * Department of Interdisciplinary Social Science, Utrecht University, Utrecht, The Netherlands \\ † ERCOMER, Department of Interdisciplinary Social Science, Utrecht University, Utrecht, The Netherlands
}

Correspondence

Maykel Verkuyten, Department of Interdisciplinary Social Science, Utrecht University, Heidelberglaan 2, Utrecht, Utrecht, 3584 CS, The Netherlands. E-mail: m.verkuyten@uu.nl

Received: 12 July 2015

Accepted: 30 March 2016

http://dx.doi.org/10.1002/ejsp.2210

Keywords: unity, political orientation, education, autochthony, deprovincialization

\begin{abstract}
Using data from three national surveys, the present research investigates among the native Dutch (Studies 1 to 3) and three immigrant-origin groups (Study 3) the endorsement of a shared sense of national belonging across cultural differences. The endorsement is examined in relation to political orientation and education, and sociocultural (deprovincialization) and egalitarian (autochthony) beliefs. In all three studies, a more right-wing orientation and lower education were associated with lower endorsement of common national belonging. Furthermore, deprovincialization and autochthony were independent mediating beliefs in these associations. The findings were similar for native majority members and immigrants, with the exception of the role of autochthony belief. The results are discussed in relation to future research on cultural diversity and the societal importance of developing a shared sense of belonging despite group differences.
\end{abstract}

'[since 2002] Dutch politicians have realized that electoral success depends on taking "autochthony" seriously. Since then the defence of "autochthonous cultural heritage" has become a dominant theme, together with the idea that more pressure is needed to make immigrants integrate into this elusive culture' -Geschiere (2009, p. 19).

Immigration and increasing cultural diversity challenge the nature of the national community (Uberoi, 2008). It raises questions about national belonging, (in) equalities and traditional cultural values (Kundnani, 2007). Diversity can lead to a lack of feelings of belonging together, which is considered a prerequisite for national solidarity, a unified society and effective democracy. Hence, proponents of cultural diversity argue that a well-functioning society needs a sense of shared belonging across differences (e.g., Cantle, 2012; Rattansi, 2011 ; Taylor, 2012). In contrast to multiculturalism with its emphasis on recognizing relatively separate and stable minority identities, it is argued that a non assimilationist notion of commonality is required: a superordinate national identity against a background of subgroup cultural differences (unity in diversity).

Social psychological research demonstrates that a common group identity is a promising approach for improving intergroup relations (Gaertner \& Dovidio, 2000, but see Wenzel, Mummendey, \& Waldzus, 2007). A sense of common belonging improves outgroup attitudes, stimulates out-group helping, and predicts majority members' efforts to help immigrants to integrate and obtain equitable socio-economic positions (Kunst, Thomsen, Sam, \& Berry, 2015). This raises the important question of when and why people endorse the notion of common national belonging. Some sections of the population are likely to support this notion whereas other sections will not, and this difference might be related to important societal cleavages.

Political and educational polarization is considered defining features of the early 21 st century Western societies. Although the higher educated compared with the lower educated tend to have a more right-wing political orientation, the relationship is not very strong in the European context (Barone, Lucchini, \& Sarti, 2007; Cornelis \& Van Hiel, 2014). Thus, political orientation and level of education represent two separate and important societal cleavages, with people on the political right and the political left, as well as the higher and lower educated, being increasingly apart attitudinally, ideologically and in terms of lifestyle (Bovens, Dekker, \& Tienteijer, 2014; Layman, Carsey, \& Horowitz, 2006; Valdesolo \& Graham, 2016). These cleavages are also salient in relation to questions of immigration and cultural diversity. There is consistent and robust evidence that rejection of immigrants and diversity is stronger among the politically right than among the left (e.g., Chambers, Schlenker, \& Collison, 2012; Sears \& Henry, 2003; Van Prooijen, Krouwel, Noiten, \& Eendebak, 2015) and among the lower educated compared with the higher educated (e.g., Coenders \& Scheepers, 2003; Meeusen, De Vroome, \& Hooghe, 2013; Ostapczuk, Musch, \& Moshagen, 2009). There is hardly any 
research, however, that examines the role of political orientation and education simultaneously, their relations with the endorsement of common national belonging and the justifying beliefs involved in these relations. The current research examines these issues using existing survey data collected among national samples in the Netherlands.

Our first aim is to examine the endorsement of common national belonging and whether this endorsement is independently associated with political orientation and educational level. Thus, we want to make a societal psychological contribution to the diversity literature by examining how important societal cleavages relate to individual attitudes and beliefs (Himmelweit $\&$ Gaskell, 1990). The second aim is to examine whether the constructs of autochthony (primo-occupancy) and deprovincialization (non-parochialism) play a mediating role in these relations. These constructs feature prominently in West European debates about immigration and cultural diversity (e.g., Ceuppens, 2011; Geschiere, 2009) but so far have received relatively little attention in social psychology (Martinovic \& Verkuyten, 2013; Pettigrew, 1997). Autochthony relates to beliefs about equality and deprovincialization to beliefs about sociocultural traditions. In trying to make a novel contribution to the literature, we want to find out if both play a unique and complementary role, in addition to well-known indicators of equality (social dominance orientation) and traditionalism (conformity), as well as ethnic in-group identification and intergroup contact as two important social psychological predictors of intergroup attitudes. Our third aim is to examine the endorsement of common national belonging and its correlates among the native Dutch (Studies 1 to 3) and samples of the three largest immigrant-origin groups in the Netherlands (Study 3). The notion of unity in diversity tries to be inclusive for all groups, and therefore, it is important to examine the perspective of majority and minority group members.

\section{Political Orientation}

It has been argued and shown that two stable, core dimensions capture the most important differences between right-wing and left-wing political orientations (Jost, Glaser, Kruglanski, \& Sulloway, 2003a, 2003b). The first one concerns attitudes towards sociocultural change versus tradition, and the second one relates to questions of egalitarianism and (in)equality. Politically, right-wing orientations are considered to be associated with feelings of fear and uncertainty resulting in resistance to change and opposition to equality (Jost et al., 2003b). For example, in a large-scale study in the Netherlands, it was found that feelings of socio-economic fear mediate the relation between political extreme orientations and the derogation of minority groups, including immigrants (Van Prooijen et al., 2015). People on the political right tend to avoid cultural change and disruption and to justify inequalities between individuals and groups. This means that compared with the political left, the right is more prone to endorse traditionalism, conformity and belief in inequality (e.g., Jost, 2006; Wetherell, Brandt, \& Reyna, 2013). These differences in beliefs can be expected to explain why people on the political right will be less in favour of common national belonging that acknowledges cultural diversity. Such a representation implies cultural changes and greater equality for immigrant-origin groups, and this is difficult to reconcile with, for example, social conformity and social dominance beliefs (Duckitt, Wagner, du Plessis, \& Birum, 2002). In addition, the constructs of autochthony (equality dimension) and deprovincialization (traditionalism dimension) might independently explain the expected link between political orientation and the endorsement of common national belonging.

In political theory, the term historical right refers to the right to a piece of land because of first occupancy (Gans, 2001; Murphy, 1990). The term autochthony literally means being born from the soil and typically involves the claim of primo-occupancy with the related sense of ownership and entitlements. For many people, nationhood is about homeland, and autochthony is a strong justification for territorial and nationalist sovereignty claims and a core issue in violent conflicts and war (Toft, 2014). Autochthony beliefs are also used to exclude newcomers and to justify prejudice and inequalities towards immigrant-origin groups in Western Europe (Ceuppens, 2011; Geschiere, 2009; Martinovic \& Verkuyten, 2013). It has an 'implicit call for excluding strangers ("allochthons"), whoever they may be' (Ceuppens \& Geschiere, 2005, p. 386). Autochthony has become a key notion in discussions about immigration and cultural diversity among the political right and also for middle-of-the-road parties. Arguments about primo-occupancy are used to deny immigrants equal participation in the receiving society. The notion of autochthony is particularly salient in the Netherlands where it was introduced as a policy term in the 1980s, in order to make a distinction between natives (autochthones) and immigrants (allochthones). We propose that an appeal to autochthony, as a belief that gives prerogatives to natives and creates inequality, is particularly likely among the political right. Thus, we expected that a more right-wing political orientation would be related to stronger endorsement of autochthony and thereby to lower support of common national belonging, which undermines natives' exclusive ownership claims.

Individuals on the right end of the political spectrum tend to prefer the status quo and have a more provincial or parochial world view that provides security and stability, compared with those on the left, who more strongly embrace social change and openness (Jost et al., 2003b; Thorisdottir, Jost, Liviatan, \& Shrout, 2007). Uncertainty fosters endorsement of in-group norms, values and beliefs and makes people more resistant to developments or changes that challenge their cultural world view (Hogg, 2007). A parochial world view implies that others are judged from one's own cultural point of view. The in-group is seen as the centre of the world, and its norms, customs and beliefs provide 
the self-evident and invariant standards for judgment. In contrast, deprovincialization implies a less groupcentric world view whereby more pluralistic standards of judgment develop (Pettigrew, 1997). It implies openness and a broadening of one's cultural horizon by putting one's taken-for-granted cultural standards into perspective and acknowledging and valuing the cultural world view of others. The feelings of uncertainty and fear that are associated with political right-wing orientations (Jost et al., 2003b) can be expected to be related to more parochial rather than deprovincial beliefs. Thus, we expected that a more right-wing orientation would be associated with lower deprovincialization and thereby with lower endorsement of common national belonging.

\section{Education}

Education is an increasingly important and separate dividing line in European societies and in the Netherlands in particular (Bovens et al., 2014). A robust empirical finding is that higher education is associated with lower levels of intolerance and ethnocentrism, and this association cannot be explained by the greater tendency of the higher educated to respond in a socially desirable way (e.g., Coenders \& Scheepers, 2003; Ostapczuk et al., 2009; Wagner \& Zick, 1995). There are several reasons for this finding, and two important ones have to do with cognitive ability and perceived competition.

First, the educational system is an important source of influence on the development of social attitudes and values. Education is associated with cognitive ability and flexibility (Bobo \& Licari, 1989; Ohlander, Batalova, $\&$ Treas, 2005), making the higher educated, for example, better able to understand the importance of basic norms of equality and tolerance underlying the democratic culture (Vogt, 1997). Furthermore, higher levels of cognitive ability make it easier to generalize the principles of tolerance and equality to minority groups (Gaasholt \& Togeby, 1995).

Second, the higher educated tend to have more privileged positions with relatively high occupational prestige. According to ethnic competition theory (Scheepers, Gijsberts, \& Coenders, 2002), they are less likely to face and perceive increased competition over scarce resources (e.g., housing and jobs) from immigrants. Furthermore, while the higher educated can benefit from globalization processes, the lower educated with their more vulnerable position are more likely to be negatively affected by increasing globalization with its higher movement and inflow of people from abroad. Globalization increases uncertainties more among the lower than higher educated. As a result, the lower educated more strongly feels the need to reduce these uncertainties and therefore rely more on the nation and traditional culture to provide security (Bekhuis, Lubbers, \& Verkuyten, 2014).

Higher education has been consistently found to be associated with lower authoritarianism and lower social dominance orientation (e.g., Shaefer, 1996; Sidanius, Pratto, \& Bobo, 1996). In addition, it can be expected that higher education is associated with lower autochthony beliefs and higher deprovincialization. The more secure position of the higher educated makes it likely that they less strongly endorse natives' ownership of the nation, and their greater cognitive flexibility makes a more nuanced understanding of the in-group culture more likely. Thus, for the native majority, we expected higher education to be associated with stronger endorsement of common national belonging through lower autochthony and higher deprovincialization.

\section{Majority and Minority Groups}

In its emphasis on unity in diversity, a common national identity tries to be inclusive for all groups. In the European context, however, such an identity has more to offer to ethnic minorities than the native majority because it is for the latter more threatening to their cultural dominance and higher status position (Verkuyten, 2014). Thus, we can expect that the majority is less supportive of common national belonging than minorities. Yet, also for minority group members, beliefs about the importance of tradition and inequality are more likely among the political right compared with the left, and higher educated minorities will have greater cognitive ability, have more prestigious occupations and will be more able to benefit from globalization.

However, some of the beliefs mediating the relations between political orientation and education with the endorsement of common national belonging might be different for majority and minority groups. Specifically, autochthony beliefs that justify national ownership claims of natives can be expected to be less relevant for minority members' endorsement of a shared sense of national belonging. With its emphasis on seniority and history, autochthony is a nativist ideology that excludes immigrant-origin groups. This means that for minorities autochthony belief probably is not related to the endorsement of common national belonging and therefore does not mediate the associations between political orientation and education with common belonging. However, a more deprovincialized or nuanced view of Dutch culture can be expected to be associated with a stronger endorsement of common national belonging, also among minorities. The reason is that for minority members such a view implies the rejection of 'Dutch-centrism', which makes it easier to argue for change and the development of unity in diversity. Furthermore, for minorities, a stronger political left orientation, with its lower traditionalism, and a higher level of education, with its greater cognitive abilities, can also be expected to be associated with higher deprovincialization. We will examine these possible associations in Study 3 where we compare majority and minority members.

\section{The Current Research}

Our expectations are tested using existing survey data from three national samples from the Netherlands. ${ }^{1}$ 
Thus, we respond to concerns about the use of convenience samples for the generality of findings and theoretical conclusions (Henrich, Heine, \& Norenzayan, 2010), especially in relation to out-group evaluations (Henry, 2008). The use of relatively large national samples is particularly important because we can only adequately examine the roles of political orientation and education when the politically right and left, as well as lower and higher educated, are sufficiently represented. Furthermore, the Netherlands provides an adequate setting because of the rather equal support for the political left and right among the population, with both the far right and the far left having substantial and equal political and electoral significance (both received around 10 per cent of the votes in the last general election). The use of national samples has the additional advantage that in the analyses we can control statistically for demographics, such as age and gender, and also for the possible confounding variables of ethnic in-group identification (Studies 1 to 3 ) and intergroup contact (Studies 2 and 3). Finally, by reporting three studies, we respond to increasing concerns about the lack of replication research in (social) psychology and the need for (partial) replication studies that improve precision and test robustness and generalizability (Simons, 2014).

\section{Study 1}

Among the native Dutch, study 1 examines to what extent education and also political orientation are associated with the support of common national belonging and whether these associations can be explained by autochthony beliefs (equality dimension) and endorsement of deprovincialization (traditionalism dimension). In order to test whether autochthony and deprovincialization form two independent mediating mechanisms, we also considered the well-known constructs of social conformity and social dominance orientation. Social conformity is a central aspect of authoritarianism and relates to the traditionalism dimension, and social dominance orientation relates to the equality dimension. We expected that autochthony and deprovincialization would play a mediating role, over and above social conformity and social dominance orientation, and ethnic in-group identification.

\section{Method}

Data and respondents. Eight hundred and two adults, drawn from a nationally representative pool of the native Dutch population, took part in an online study. The sample was selected by a research

\footnotetext{
${ }^{1}$ The survey data used in Studies 1 to 3 contained various other constructs, and parts of these data have been analysed in other papers (e.g. Hindriks, Verkuyten, \& Coenders, 2014; Verkuyten \& Martinovic, 2015; Verkuyten, Martinovic, \& Smeekes, 2014). However, the current theoretical focus and analyses are novel, and the findings of the three studies have not been published previously.
}

consultancy company (TNS-NIPO), which maintains a database of Dutch people who regularly participate in surveys in return for remuneration. The obtained sample covered various segments of the Dutch population in terms of age, gender, education, household size and the region of residence. The respondents were aged between 18 and 87 years $(M=50.68, S D=17.17)$, and women made up 50 per cent.

Measures. To assess political orientation, the wellknown Political Self-placement Scalea (Jost, 2006) was used. The scale had five categories: (1) left, (2) centre left, (3) centre, (4) centre right and (5) right: 29.8 per cent of the respondents placed themselves at the political left, 25.6 per cent at the right and 44.6 per cent in the middle.

Educational level was captured on a 7-point scale that referred to the highest completed level: (1) primary school, (2) lower secondary, (3) middle secondary, (4) vocational, (5) higher secondary (preparing students for a university), (6) undergraduate and (7) postgraduate level. Five and a half per cent of the respondents had completed only primary school, and 24.7 per cent had a tertiary degree. We treated both education and political orientation as continuous variables in the analyses, and they were only weakly associated (Table 1).

The study included four mediators, all measured with multiple items rated on a 7-point scale ranging from 1 (strongly disagree) to 7 (strongly agree). Two of the mediators (social dominance orientation and autochthony) tapped into the egalitarian dimension of social attitudes, while the other two (conformity and deprovincialization) dealt with the traditionalism dimension (Duckitt, 2001).

Social dominance orientation (SDO-E) (Sidanius $\delta$ Pratto, 1999) consisted of four items: 'We should treat each other as much as possible as equals', 'Equality is an important principle for me', 'We would have fewer problems if we treated people more equally' and 'It is important to treat other groups as equals' $(\alpha=.84)$. The items represent the equality aspect of the SDO-E (Ho et al., 2012), and we recoded the items so that a higher score stands for more preference for non-egalitarian beliefs, that is, more social dominance orientation. ${ }^{2}$

Four items about entitlements for primo-occupants were employed to measure autochthony (Martinovic \& Verkuyten, 2013): for example, 'The original inhabitants of a country are more entitled than newcomers' and 'Every country belongs to its original inhabitants'. A higher score means a stronger endorsement of autochthony $(\alpha=.92)$, and by extension, more support for inequality.

\footnotetext{
${ }^{2}$ The dataset also included four items of the dominance aspect of SDO (SDO-D), but these items did not load on a common factor with SDO-E, in accordance with Ho et al. (2012). Moreover, the items for SDO-D did not scale very well, with an alpha of .62. Therefore, we focused only on SDO-E as an indicator of opposition to equality.
} 
Table 1. Means, SDs and correlations of the core constructs

\begin{tabular}{|c|c|c|c|c|c|c|c|c|c|}
\hline & & 1 & 2 & 3 & 4 & 5 & 6 & Mean & $S D$ \\
\hline & Study 1 & & & & & & & & \\
\hline 1. & Common belonging & - & & & & & & 4.15 & 1.51 \\
\hline 2. & Autochthony & $-.54 * * *$ & - & & & & & 4.05 & 1.46 \\
\hline 3. & Deprovincialization & $.55^{* * *}$ & $-.50 * * *$ & - & & & & 5.37 & 0.96 \\
\hline 4. & Political orientation & $-.29 * * *$ & $.30 * * *$ & $-.24 * * *$ & - & & & 2.92 & 1.04 \\
\hline 5. & Education & $.28 * * *$ & $-.26^{\star * *}$ & $.28 * * *$ & $-.07 *$ & - & & 5.03 & 1.68 \\
\hline 6. & SDO-E & $-.51 * * *$ & $.42 * * *$ & $-.56^{* * *}$ & $.26^{* * *}$ & $-.18 * * *$ & - & 2.72 & 0.98 \\
\hline 7. & $\begin{array}{l}\text { Conformity } \\
\text { Study } 2\end{array}$ & $-.40 * * *$ & $.52 * * *$ & $-.35 * * *$ & $.30 * * *$ & $-.30 * * *$ & $.22 * * *$ & 4.60 & 1.11 \\
\hline 1. & Common belonging & - & & & & & & 4.15 & 1.47 \\
\hline 2. & Autochthony & $-.42 * * *$ & - & & & & & 4.33 & 1.45 \\
\hline 3. & Deprovincialization & $.47 * * *$ & $-.34^{* * *}$ & - & & & & 5.33 & 0.95 \\
\hline 4. & Political orientation & $-.33 * * *$ & $.29 * * *$ & $-.22 * * *$ & - & & & 2.99 & 1.08 \\
\hline 5. & Education & $.20 * * *$ & $-.23^{* * *}$ & $.33 * * *$ & $-.07 *$ & - & & 5.21 & 1.74 \\
\hline
\end{tabular}

Note: SD, standard deviation; SDO-E, social dominance orientation.

${ }^{*} p<.05$;

$* * * p<.001$.

As an indicator of sociocultural traditionalism, we measured a central facet of right-wing authoritarianism-conformity-using three items (Sniderman \& Hagendoorn, 2007): 'One should better watch out for people who act differently than the mainstream', 'Rules are made to be adhered to, and people should not try to change them' and 'People should stick to the creed "if you just behave normally, you already behave crazily enough"' $(\alpha=.70)$.

Existing research on deprovincialization tends to use rather narrow operationalizations, namely, in-group identification or in-group attitude (Hodson \& Hewstone, 2012). We developed four questions that more directly tap into a non-absolute or non-'Dutch-centric' understanding of Dutch culture (Martinovic \& Verkuyten, 2013): 'The Dutch culture is certainly not better than other cultures', 'One should always try to adopt a broader perspective than only the Dutch perspective', 'How we perceive the world in the Netherlands is only one of the many possibilities' and 'One should always nuance one's own worldview and not make it sacred' $(\alpha=.86)$.

The dependent variable common national belonging was measured with three questions that asked about the importance of having an overarching national community, despite cultural diversity. Thus, the emphasis was on the unity aspect of unity in diversity, and this was assessed with items adapted from Gaertner, Rust, Dovidio, Bachman, and Anastasio (1996): 'Even though the Netherlands is a culturally diverse society, I have the feeling we all belong to one community', 'In spite of the cultural differences, all groups together make up Dutch society' and 'Despite all the differences, I often have the feeling that we are one country and that we have to work together' $(\alpha=.90)$.

Table 1 shows the correlations, mean scores and standard deviations (SDs) for the various constructs. We additionally controlled for age (in years), gender $(1=$ female $)$ and ethnic in-group identification $(\alpha=.93)$, which was assessed by asking the respondents to respond to four items (e.g., 'I identify strongly with the Dutch' and 'My Dutch identity is important for how I feel about myself') taken from previous research in the Netherlands (Verkuyten, 2014).

\section{Results and Discussion}

Measurement model. We ran a confirmatory factor analysis in MPLUs (version 7) and verified that the items for common national belonging, SDO-E, autochthony, conformity, deprovincialization and ingroup identification all formed empirically distinct latent constructs. A model with six latent factors fitted the data well, $\chi^{2}(194)=627.25, p<.001$, comparative fit index $(C F I)=0.963$, Tucker-Lewis index (TLI) $=0.956$, root mean square error of approximation $(R M S E A)=0.053($ low $=0.048$, high $=0.057)$, standardized root mean square residual $(S R M R)=0.049$. We further checked that the two mediators representing the (anti)egalitarian dimension (SDO-E and autochthony) are empirically distinct. A measurement model in which the items representing these two constructs were forced on a common factor yielded a worse fit, $\chi^{2}(199)=$ $1879.81, p<.001, C F I=0.858, T L I=0.835, R M S E A=$ 0.103 (low $=0.098$, high $=0.107), \quad S R M R=0.095$, as demonstrated by a significant chi-squared difference test, $\Delta \chi^{2}=1252.56, \Delta d f=5, p<.001$. Similarly, forcing conformity and deprovincialization (the sociocultural dimension) to load on a common factor also resulted in a worse fit, $\chi^{2}(199)=1102.35, p<.001, C F I=0.924$, $T L I=0.911, R M S E A=0.075 \quad($ low $=0.071$, high $=0.080$ ), $S R M R=0.081 ; \Delta \chi^{2}=475.10, \Delta d f=5, p<.001$. Any other combination of five factors had a worse fit than the proposed six-factor model.

Predicting common national belonging. To test our hypotheses, we estimated a structural model of common belonging, with political orientation and education as the main independent variables and SDO-E, autochthony, conformity and deprovincialization as 
the mediators. ${ }^{3}$ We controlled for age, gender and ingroup identification in relation to the dependent variable and all four mediators. ${ }^{4}$ In total, we specified eight indirect paths: four from political orientation to common belonging and four from education to common belonging, via SDO-E, autochthony, conformity and deprovincialization. We requested confidence intervals (CIs) for the indirect effects based on bootstrapping with 5000 replacement samples (Preacher \& Hayes, 2008). A 95 per cent $\mathrm{CI}$ that does not include zero indicates an indirect effect.

The coefficients for the hypothesized paths are displayed in Figure 1 and support all of our predictions. Native Dutch with a more right-wing political orientation and those with a lower level of education tended to support equality less, endorse autochthony more, be more conformist and show a less deprovincialized attitude. Autochthony and conformity were in turn related to a weaker, and equality and deprovincialization to a stronger, endorsement of common national belonging.

All eight indirect paths were significant. More rightwing political orientation was related to lower common belonging via higher SDO-E, $\beta=-.072, t=-4.29$, $p<.001$, 95 per cent CI $[-0.103,-0.040]$; higher autochthony, $\beta=-.041, t=-2.99, p=.003,95$ per cent CI $[-0.069,-0.014]$; higher conformity, $\beta=-.048$, $t=-2.649, p=.013,95$ per cent CI $[-0.086,-0.010]$; and lower deprovincialization, $\beta=-0.044, t=-3.23$, $p=.001,95$ per cent CI $[-0.071,-0.016]$. Furthermore, education was related to higher common belonging via lower SDO-E, $\beta=.053, t=3.78, p<.001,95$ per cent CI $[0.024,0.081]$; lower autochthony, $\beta=.038, t=2.689$, $p=.007,95$ per cent CI [0.012, 0.064]; lower conformity, $\beta=.043, t=2.42, p=.016,95$ per cent CI [0.008, 0.079]; and higher deprovincialization, $\beta=.060, t=3.86$, $p<.001,95$ per cent CI [0.030, 0.091]. The remaining direct relationships between political orientation and common belonging, and education and common belonging, were not significant, indicating full mediation. ${ }^{5}$

\footnotetext{
${ }^{3}$ In all three studies, we also tested whether there were quadratic associations between political orientation and education, on the one hand, and the endorsement of common national belonging and the mediators, on the other hand. There was no systematic evidence for such quadratic relations in any study. Furthermore, in all three studies, we also examined whether there was an interaction effect between political orientation and education on the different measures, and there was no systematic evidence for this either (findings are available on request). ${ }^{4}$ In all three studies, we also examined the associations without the control variables. In all three studies, this resulted in substantially the same findings, leading to the same conclusions (findings are available upon request).

${ }^{5}$ Regarding the control variables, higher Dutch identifiers endorsed autochthony more, $\beta=.324, t=17.01, p<.001$; were more conformist, $\beta=.301, t=5.67, p<.001$; and less deprovincial, $\beta=-.093, t=-2.13$, $p=.033$. Dutch identification was not related to common national belonging, $\beta=.032, t=0.087, p=.383$; or to SDO-E, $\beta=.027, t=0.053$, $p=.607$. Men and women only differed on autochthony, with women endorsing it less than men, $\beta=-.064, t=-2.027, p=.043$. Older respondents were more deprovincial, $\beta=.115, t=3.352, p=.001$, and endorsed autochthony less, $\beta=-.099, t=-3.038, p=.002$.
}

In line with our hypotheses, the results of Study 1 demonstrate that political orientation and education were important and independent predictors of common national belonging. Furthermore and in addition to conformity and social dominance, autochthony and deprovincialization were independent beliefs linking political orientation and education to the endorsement of national unity that recognizes diversity. Thus, majority members who were oriented towards the political right, and also those with lower levels of education, were found to less strongly endorse common national belonging, via sociocultural beliefs (deprovincialization, in addition to social conformity) and equality beliefs (autochthony, in addition to social dominance orientation).

\section{Study 2}

Study 2 tried to replicate the mediating roles of autochthony and deprovincialization beliefs among a different national sample of the native Dutch population, while taking intergroup contact into account as an additional possible confounding factor. People with a more left-wing political orientation and the higher educated might have more positive contacts with members of immigrant-origin groups, and these contacts might lead to a more deprovincialized view on Dutch culture, less support for nativist ideologies such as autochthony and more acceptance of cultural diversity (Hodson \& Hewstone, 2012; Pettigrew \& Tropp, 2011). Therefore, it is important to examine whether the associations found in study 2 are not due to intergroup contact.

\section{Method}

Data and respondents. Nine hundred twentytwo adults from a nationally representative pool of native Dutch population completed an online survey. Similar to Study 1, the sample was drawn by TNS-NIPO, but people who took part in Study 1 were not approached for participation in the second study. The respondents were between 18 and 88 years old $(M=49.86$, $S D=17.18)$, and women made up 47.9 per cent of the sample.

Measures. The measures for political orientation, education, autochthony $(\alpha=.93)$, deprovincialization $(\alpha=.86)$ and common national belonging $(\alpha=.90)$ were identical to those of Study 1. Conformity and social dominance orientation were not available in the dataset for Study 2. Regarding political orientation, 28 per cent of the respondents placed themselves on the political left, 28 per cent on the right and 44 per cent in the middle. Concerning education, 5.2 per cent of the respondents had completed only primary school and 30.5 per cent had a tertiary degree. We again controlled for age (in years), gender ( $1=$ female) and in-group identification (same items as in Study 1, 


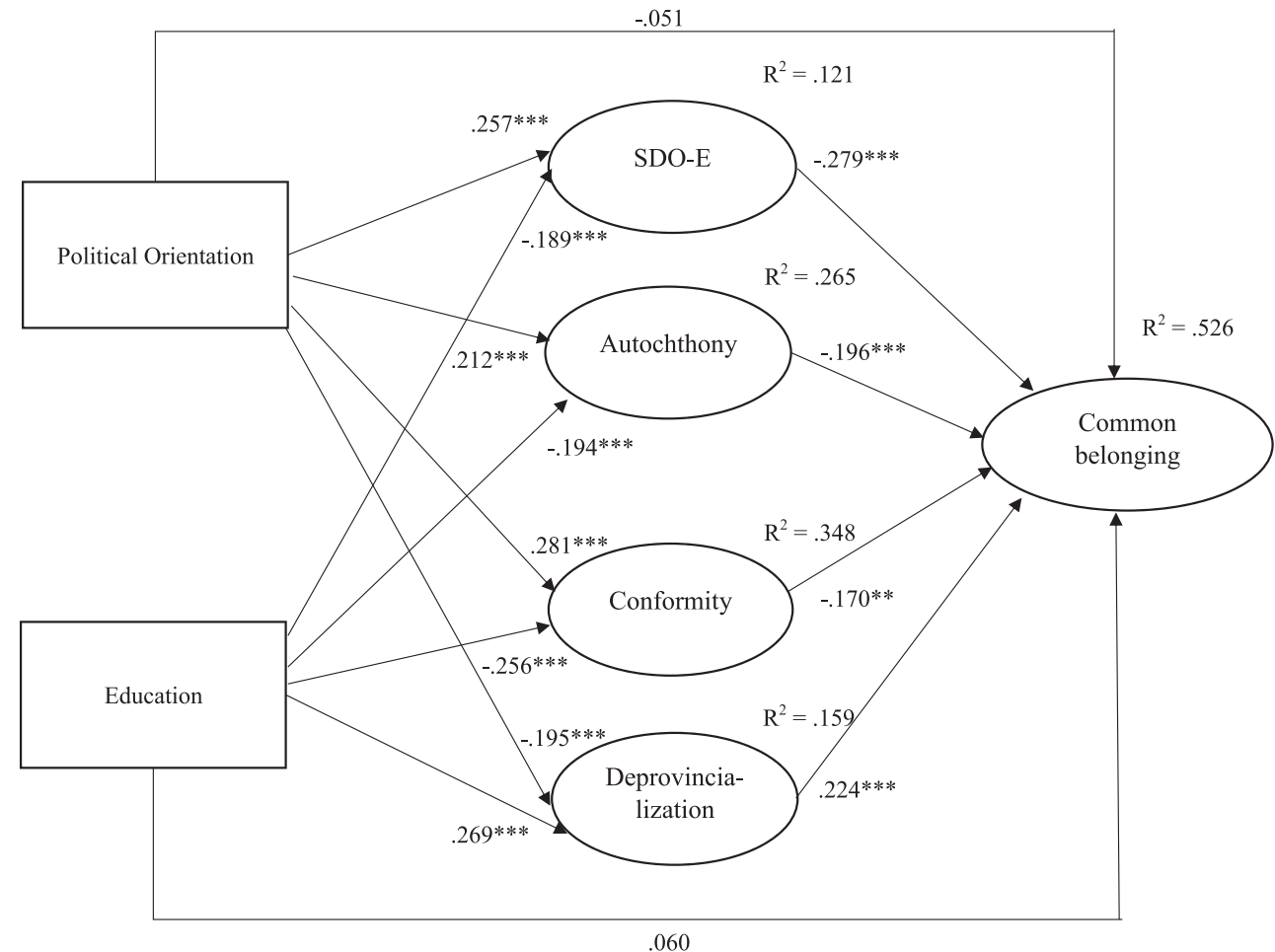

Note: Model fit: $\chi^{2}(264)=819.49, p<.001, \mathrm{CFI}=.96$, RMSEA $=051$, SRMR $=.050$. Standardized coefficients presented; the correlations between the four mediators were accounted for (SDO-E and autochthony, $\beta=.394, p<.001$; SDO-E and conformity, $\beta=.208, p<.001$; SDO-E and deprovincialization, $\beta=-.590, p<.001$; autochthony and conformity, $\beta=.533, p<.001$; autochthony and deprovincialization, $\beta=-.443, p<.001$; conformity and deprovincialization, $\beta=-.349, p<.001$ ). Contro variables age, gender and ethnic identification were included in the model. ${ }^{* *} \mathrm{p}<.01,{ }^{* * *} \mathrm{p}<.001$.

Fig. 1: The effects of political orientation and education on common national belonging, mediated by social dominance orientation (SDO-E), autochthony, conformity and deprovincialization $(N=802)$

$\alpha=.94)$. We additionally controlled for intergroup contacts, which was measured by asking respondents how often they had contact with each of the following ethnic minority groups in the Netherlands: Turks, Moroccans, Surinamese, Antilleans and other ethnic minority groups, on a scale from 1 (never) to 7 (everyday). These five items were combined into a scale $(\alpha=.89)$. Table 1 shows the correlations, mean scores and SDs for the main constructs. The correlations are similar to those reported in Study 1, with the association between political orientation and education again being very small.

\section{Results and Discussion}

We ran a confirmatory factor analysis in MPLUS (version 7) and verified that the items for common belonging, autochthony, deprovincialization, interethnic contact and in-group identification all formed empirically distinct latent constructs. A model with five latent factors fit the data well, $\chi^{2}(160)=513.49, p<.001$, $C F I=0.974, T L I=0.969, R M S E A=0.049 \quad($ low $=0.044$, high $=0.054)$ and $S R M R=0.032$.

Subsequently, we estimated a structural model, with political orientation and education as the main independent variables, and autochthony and deprovincialization as the mediators. We controlled for age, gender, interethnic contact and in-group identification in relation to common national belonging and the two mediators. In total, we specified four indirect paths: two from political orientation to common belonging and two from education to common belonging, via autochthony and deprovincialization. We requested CIs for the indirect effects based on bootstrapping with 5000 replacement samples.

Figure 2 shows the coefficients for all the hypothesized paths, and the findings are in line with our expectations. Dutch people with a more right-wing political orientation, as well as those with lower levels of education, tended to endorse autochthony more and showed a less deprovincialized attitude. Autochthony was in turn related to weaker, and deprovincialization to stronger, support of common national belonging. ${ }^{6}$

Further, all four indirect paths were significant. More right-wing political orientation was related to less common belonging via higher autochthony, $\beta=-.075$, $t=-5.47, p<.001,95$ per cent CI $[-0.097,-0.040]$,

${ }^{6}$ Higher Dutch identifiers endorsed autochthony more, $\beta=.220$, $t=5.30, p<.001$, and showed stronger support for common national belonging, $\beta=.107, t=2.830, p=.005$. Dutch identification was not related to deprovincialism, $\beta=-.066, t=-1.597, p=.383$. Intergroup contact was not significantly related to any of the measures $\left(p_{\mathrm{s}}>.13\right)$. There were no significant gender differences. Older participants, again, were more deprovincial, $\beta=.138, t=3.816, p<.001$, and endorsed autochthony less, $\beta=-.089, t=-2.669, p=.008$. 


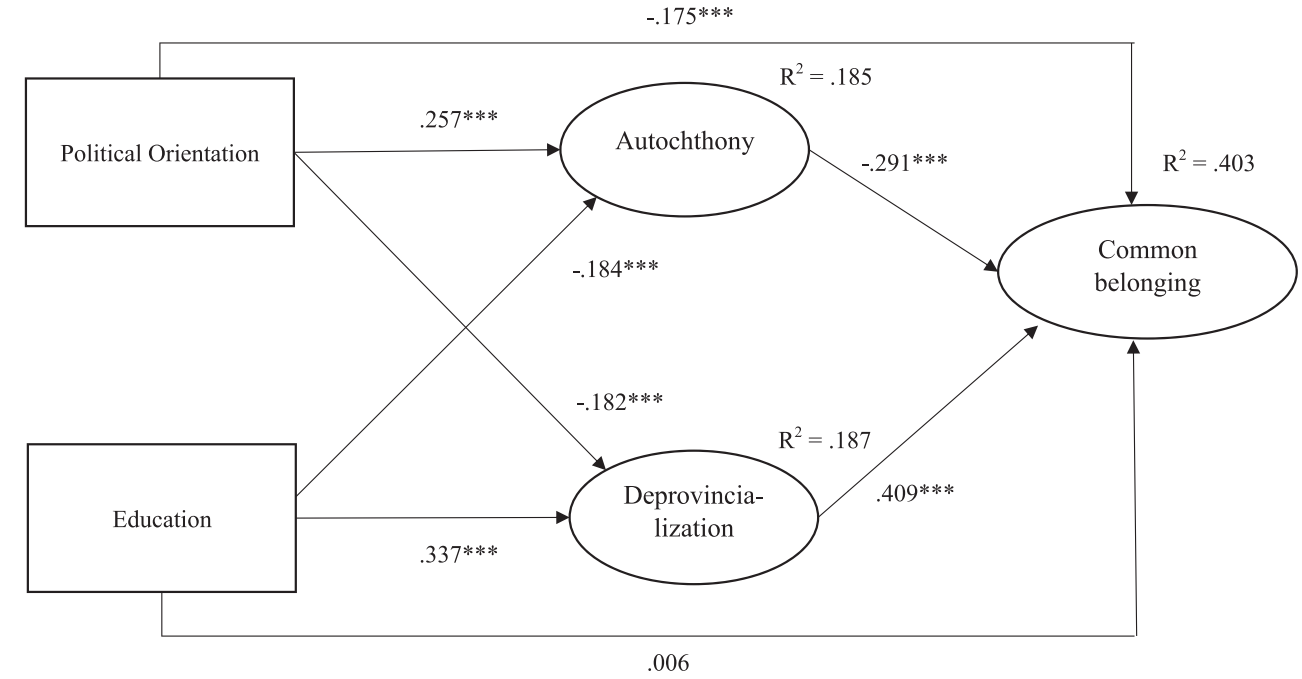

Note: Model fit: $\chi^{2}(220)=626.66, p<.001$, CFI $=.97$, RMSEA $=.045$, SRMR $=.030$. Standardized coefficients presented; the correlations between the two mediators were accounted for (autochthony and deprovincialization, $\beta=-.218, p<.001)$. Control variables age, gender, intergroup contact and ethnic identification were included in the model. $* * * \mathrm{p}<.001$.

Fig. 2: The effects of political orientation and education on common national belonging, mediated by autochthony and deprovincialization $(N=922)$

and lower deprovincialization, $\beta=-.074, t=-4.90$, $p<.001,95$ per cent CI $[-0.099,-0.049]$. Furthermore, education was related to greater common belonging via lower autochthony, $\beta=.053, t=4.83, p<.001$, 95 per cent CI $[0.035,0.072]$, and higher deprovincialization, $\beta=.138, t=7.92, p<.001,95$ per cent CI [0.109, 0.166]. The remaining direct relationship between education and common belonging was not significant, indicating full mediation. However, the direct relationship between political orientation and common national belonging remained significant, suggesting partial mediation.

Among a different national sample of the native Dutch population and controlling for intergroup contact, the results of Study 2 are similar to those of Study 1. It was again found that natives with a rightwing political orientation, and also those with lower education, endorsed common national belonging less and that these associations were mediated by beliefs of autochthony and deprovincialization.

\section{Study 3}

Unity in diversity implies the development of a common sense of belonging across cultural differences and involving all groups. This means that not only the perspective of the native majority population but also that of minorities should be considered. We therefore used a third study conducted among majority and ethnic minority members to examine and compare the associations and structural model found in the first two studies. Common national belonging is inclusive for minority groups and can be threatening to the dominant position of the majority group (Dovidio, Gaertner, \& Saguy, 2009). Therefore, it is likely that minority members will endorse common national belonging more strongly than the majority, yet we expected for both groups a similar pattern of associations between the different variables, but with one exception. Because autochthony beliefs justify national ownership claims of natives, we expected this construct to be less relevant for minority members' endorsement of a shared sense of belonging, than for majority members. We again controlled statistically for ethnic in-group identification and intergroup contact.

\section{Method}

Data and respondents. The data used in Study 3 were again gathered online by TNS-NIPO. The full sample consisted of 664 respondents: 173 were Dutch and 491 were part of one of three largest immigrant-origin groups of Surinamese $(N=168)$, Turkish $(N=165)$ and Moroccan $(N=158)$ background. The native Dutch respondents were between 19 and 81 years of age. Their mean age was 51.77 years $(S D=16.24)$, and 48 per cent of the Dutch respondents were female. The minority group respondents were between 18 and 84 years of age. Their mean age was 41.17 years $(S D=13.16)$, and 56 per cent of the minority group respondents were female.

Measures. The independent variables political orientation and education were measured in the same way as in the previous studies. Twenty-three per cent of the respondents answered 'don't know' to the question pertaining to their political orientation. These values were estimated using full information maximum likelihood estimation in MPLus. The dependent variable and the two mediators were also assessed with the same items: common national belonging ( $\alpha=.88$ for the majority and $\alpha=.81$ for the minority), autochthonyx (for the majority, $\alpha=.87$, and for the minority, $\alpha=.90$ ) and deprovincialization (majority, $\alpha=.87$, and minority, $\alpha=.83$ ). Table 2 presents the correlations, mean scores 


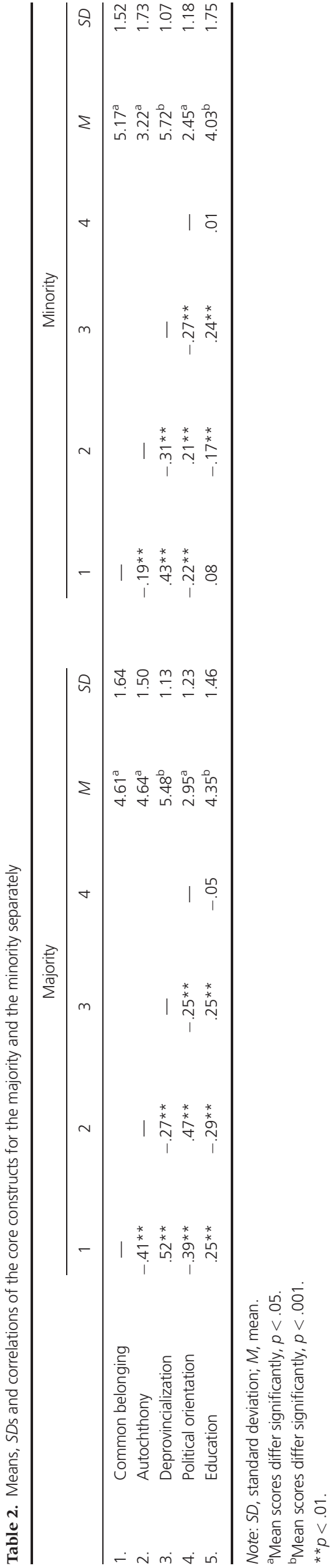

and SDs of the main concepts for the majority and minority samples separately. For both groups, there was no significant association between political orientation and education. Compared with the native Dutch, the minority members were somewhat lower educated and more oriented to the political left. As expected, they also endorsed common national belonging more strongly. Further, minority members were more supportive of a deprovincial or less Dutch-centric world view, and they were less in favour of autochthony.

Four variables were controlled for in Study 3. Two of these are demographic characteristics, namely, age (measured in years) and gender $(1=$ female $)$. Further, ethnic in-group identification was measured with two items. Respondents were asked to indicate the extent to which they identified with their ethnic in-group (for the majority, $\alpha=.79$, and for the minority, $\alpha=.90)$. We also controlled for intergroup contact. On a scale ranging from (1) never to (7) everyday, Dutch respondents were asked how frequently they had contact with each of the following four minority groups: Turks, Moroccans, Surinamese and Antilleans. The scores on these questions were averaged to form the measure of intergroup contact $(\alpha=.92)$. For minorities, intergroup contact was measured with one item (the same 7-point scale) about the frequency of contact with ethnic Dutch people.

\section{Results and Discussion}

Measurement model. MPLUS was used to estimate the model with four latent factors measuring common belonging, autochthony, deprovincialization and in-group identification. The model had a good fit, $\chi^{2}(60)=193.38$, $p<.001, C F I=0.972, T L I=0.963, R M S E A=0.058 \quad($ low $=0.049$, high $=0.067), S R M R=0.040$. As we are comparing the Dutch majority and immigrant minorities, we also estimated a multi-group confirmatory factor analysis to assess whether the items measure the same constructs and have the same meaning for the two groups. We obtained a good fit for a model with configural invariance, $\chi^{2}(120)=280.10, p<.001, C F I=0.964$, $T L I=0.954, R M S E A=0.063 \quad($ low $=0.054$, high $=0.072)$, $S R M R=0.046$, confirming that the same factor structure holds for both groups. Factor loadings on the designated latent constructs were all above 0.65 . When constraining the factor loadings to be the same across groups, a somewhat worse fit was obtained, $\chi^{2}(129)=299.31, p<.001$, $C F I=0.962, \quad T L I=0.954, \quad R M S E A=0.063 \quad($ low $=0.054$, high $=0.072$ ), $S R M R=0.063$, as indicated by a significant chi-squared difference test, $\Delta \chi^{2}=19.21, \Delta d f=9, p=.023$. Yet, releasing just one indicator of in-group identification yielded a fit similar to that of the unconstrained model, $\chi^{2}(128)=283.59, \quad p<.001, \quad C F I=0.965, \quad T L I=0.958$, $R M S E A=0.061 \quad($ low $=0.051$, high $=0.070), S R M R=0.047$, confirmed by a non-significant chi-squared difference test, $\Delta \chi^{2}=3.49, \Delta d f=8, p=.899$. This means that common belonging, autochthony and deprovincialization are fully invariant across groups, and only for the 
control variable in-group identification did we find partial invariance.

Predicting common belonging. In order to test the hypotheses, we estimated a structural model of common national belonging with education and political orientation as the main predictors and deprovincialization and autochthony as the mediators, separately for the majority and minority groups. Ingroup identification, intergroup contact, age and gender were controlled for in relation to the dependent variable as well as the two mediators. ${ }^{7}$

Initially, we constrained all the path coefficients to be equal across the two groups, and this model had an acceptable fit, $\chi^{2}(258)=549.35, p<.001, C F I=0.938$, $T L I=0.931, R M S E A=0.058($ low $=0.052, \operatorname{high}=0.065)$, $S R M R=0.070$. Subsequently, we freed the path coefficients one by one to see if this would improve the model fit, as ascertained by chi-squared difference tests. This was the case for two of the main paths, namely, between autochthony and common belonging, $\Delta \chi^{2}=10.31$, $\Delta d f=1, p<.001$, and between political orientation and autochthony, $\Delta \chi^{2}=9.22, \Delta d f=1, p<.001$. Furthermore, freeing the coefficients of the control variables age and intergroup contact in relation to deprovincialization, and of in-group identification in relation to autochthony, also significantly improved the fit of the model. With these five coefficients unconstrained, we estimated the following mediation paths: from education and political orientation via deprovincialization to common belonging and from education and political orientation via autochthony to common belonging. We again relied on CIs for the indirect effects following Preacher and Hayes (2008) bootstrapping procedure with 5000 replacement samples.

Figure 3 shows the coefficients for all the hypothesized paths. For Dutch natives and also for the minorities, right-wing political orientation and lower education were each related to stronger endorsement of autochthony, with the positive relation between political orientation and autochthony being stronger in the native sample. Furthermore, people who were more right wing, as well as those who were less educated tended to be less 'Dutch-centric', and this held again for the majority and minorities alike.

\footnotetext{
${ }^{7}$ For both the majority and minorities, ethnic in-group identification was not related to the endorsement of common national belonging, $b=0.059, t=1.677, p=.094$, but it was related to more deprovincialism, $b=0.080, t=3.139, p=.002$. The relation between ethnic identification and autochthony was positive but not significant for the Dutch majority, $b=0.169, t=1.110, p=.267$, and it was negative and significant for ethnic minorities, $b=-0.209, t=-4.489, p<.001$. Intergroup contact was not related to any of the measures for either the majority or minority group, with one exception. Minority members with more contact with the native Dutch were more deprovincial, $b=0.096$, $t=2.439, p=.015$. There were again no gender differences and also no age differences. Yet for the minority sample older people were more deprovincial, $b=0.009, t=2.998, p=.003$.
}

Deprovincialization, in turn, was associated with stronger support for common national belonging, for both groups, whereas autochthony was only for the majority related to weaker support of common belonging.

Regarding indirect effects, for both the majority and the minorities, higher education was related to higher endorsement of common belonging via higher deprovincialization, $b=0.097, t=5.30, p<.001,95$ per cent CI [0.064, 0.135]. In contrast, more right-wing political orientation was related to less common belonging via lower deprovincialization, $b=-0.144, t=-5.14$, $p<.001,95$ per cent CI $[-0.218,-0.087]$. For the majority group, higher education was also related to more common belonging via a weaker endorsement of autochthony, $b=0.050, t=2.89, p<.01,95$ per cent CI $[0.023,0.095]$, and more right-wing political orientation was related to less common belonging via a stronger endorsement of autochthony, $b=-0.159$, $t=-3.23, p=.001,95$ per cent CI $[-0.283,-0.069]$. Autochthony was not a relevant mediator for the minorities: $b=0.004, t=.49, p=.619,95$ per cent CI $[0.011,0.020]$, for education; $b=-.005, t=-0.49$, $p=.619,95$ per cent CI $[-0.032,-0.016]$, for political orientation. This is due to the fact that for the minority group autochthony was not significantly related to the endorsement of common national belonging. The relationship between education and common belonging was for both groups fully explained, as shown by the non-significant direct paths (Figure 3). However, for both groups, a direct negative relation remained between political orientation and common belonging, indicating partial mediation.

The results of Study 3 are similar to the findings of the first two studies among majority members and additionally show that some of the hypothesized mechanisms work in the same way for minority members. Specifically, it was found that, for both the majority and minorities, education was related to a stronger sense of common national belonging via stronger endorsement of deprovincialization beliefs. Furthermore, for both groups, a right-wing political orientation and lower education were independently related to weaker autochthony beliefs. However, as expected, autochthony beliefs only affected common belonging for the native majority and not for ethnic minorities. In addition to these associations, we found that minority members endorsed common national belonging more strongly than natives.

\section{General Discussion}

A culturally diverse society needs a shared sense of common national belonging that provides the necessary unity across cultural differences (Parekh, 2000; Rattansi, 2011; Taylor, 2012). We examined native majority's and immigrant minorities' endorsement of common national belonging in relation to political orientation and education as two of the main societal cleavages in most Western societies today (Bovens et al., 2014; Layman et al., 2006; Valdesolo \& Graham, 2016). 


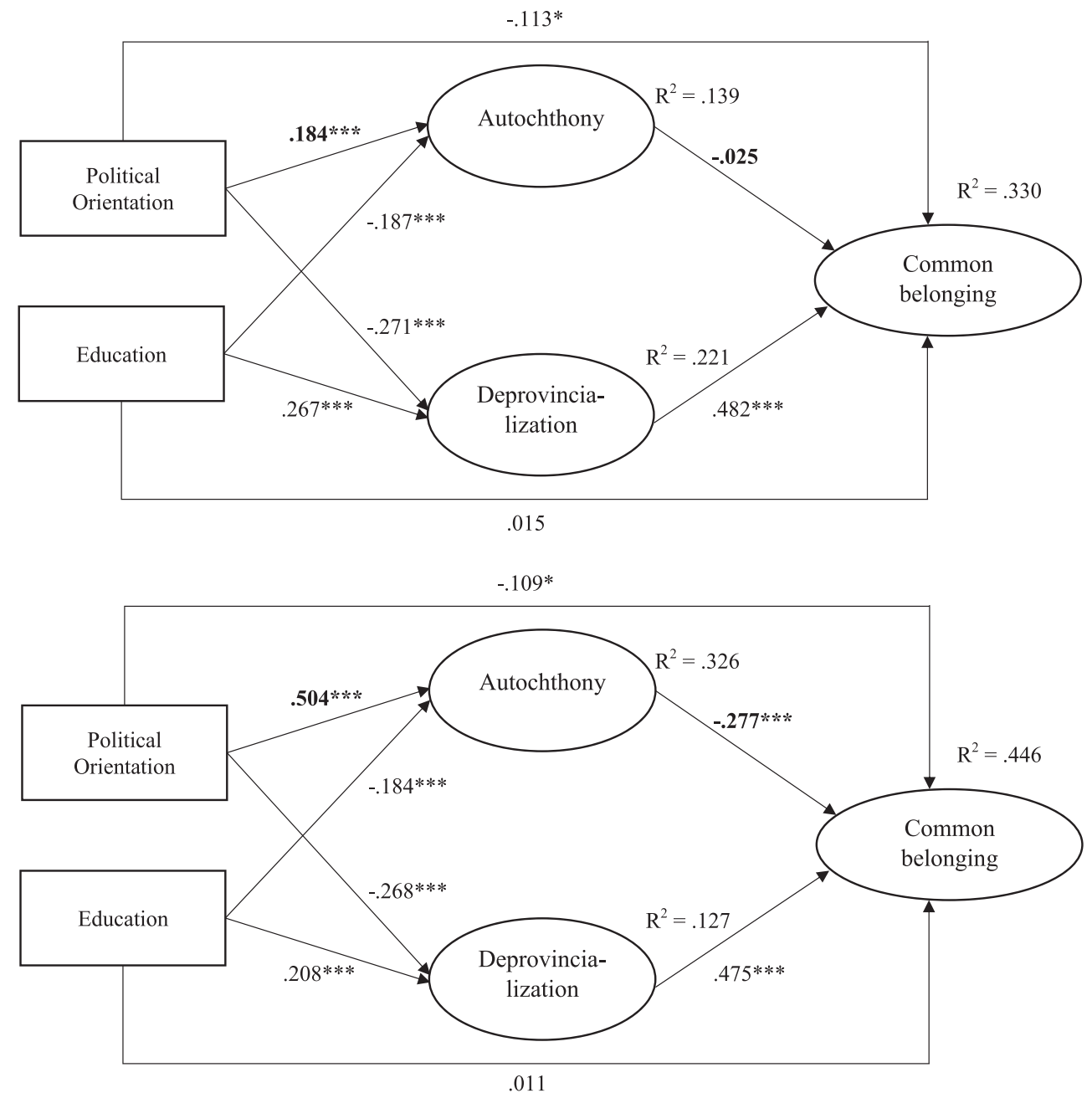

Note: Model fit: $\chi^{2}(253)=511.57, p<.001, C F I=.945$, RMSEA $=.055$, SRMR $=.059$. The first model presents the standardized coefficient for the minority, the second for the majority. Even though the path coefficients were constrained across groups, the variances were not. This results in slight differences between the groups in the standardized coefficients. The really different and freed path coefficients are written in bold. Age, gender, intergroup contact and ethnic identification were controlled for in the model, as well as the correlation between the mediators. $* p<.05, * * * p<.001$.

Fig. 3: The effects of political orientation and education on common national belonging, mediated by autochthony and deprovincialization, including four control variables, for the minority (top figure, $N=491$ ) and majority groups (bottom figure, $N=173$ ) separately

Furthermore, we examined the relatively novel constructs of autochthony and deprovincialization that feature in West European debates on immigration and cultural diversity. Arguments about ownership based on seniority and history as well as arguments about majority cultural superiority are often used to exclude minority groups and to justify prejudice and inequalities towards immigrant-origin groups (Ceuppens, 2011; Geschiere, 2009).

In three studies, we found consistent evidence that political orientation and education are only weakly interrelated and that both separately are important for understanding people's beliefs and how these relate to the endorsement of common national belonging. Research on intergroup relations typically focuses on either political orientation or education, but we considered both simultaneously. A more right-wing political orientation was associated with a weaker endorsement of common belonging because of a stronger belief in autochthony and also a weaker sense of deprovincialization. Furthermore, the higher educated were found to be more in support of common national belonging because of weaker autochthony belief and stronger deprovincialization. These results were found independently of conformism and social dominance orientation (Study 1) and while controlling for ethnic in-group identification, intergroup contact, gender and age.

In all three studies and for both the majority and minority groups (Study 3), the association between education and common national belonging was fully explained by autochthony and deprovincialization. This pattern of full mediation indicates that these two beliefs are central reasons why the higher educated are more in favour of unity in diversity than the lower educated. The higher educated tend to have a more sophisticated and nuanced understanding of the majority culture and tend to have a more secure social position, and 
these seem to make them more supportive of developing a sense of unity that recognizes cultural diversity.

In contrast to education, in Studies 2 and 3, there remained a significant direct relation between political orientation and common national belonging. This indicates that in addition to autochthony and deprovincialization other values and beliefs are important. Two of these are authoritarian values (conformity) and beliefs about group-based social hierarchies (social dominance orientation; Duckitt, 2001). In Study 1, these two constructs were included, and as a result, no direct effect of political orientation on common national belonging was found.

Study 3 also examined the perspective of immigrant minority groups, and we found that, compared with the native Dutch, minority members were more in favour of common national belonging, had a more deprovincialized view of Dutch culture and endorsed autochthony less strongly. Furthermore, for the minorities, political orientation was more weakly associated with autochthony, and this belief did not mediate the relationship between political orientation and common belonging. This indicates that for minority groups, belief in primo-occupancy and the related entitlements of natives is not very relevant and meaningful for their support of a unified but diverse society. However, educational level appeared to have a similar social psychological meaning for members of minority and majority groups. Also for the minority group, higher education was related to less autochthony and lower Dutch-centrism and, via the latter belief, to more support for common national belonging.

\section{Limitations and Future Directions}

There are two limitations that we want to discuss. The first one has to do with the construct of common national belonging that emphasizes unity despite cultural diversity. This construct has similarities with the dualidentity representation as proposed in social psychology (Gaertner \& Dovidio, 2000). Wenzel et al. (2007), however, noted that a dual-identity representation can be understood in different ways. It can refer to the simultaneous salience of superordinate and subordinate identities, which can lead to increased intergroup tensions and conflicts because of processes of in-group projection. A dual-identity representation can also emphasize the value of minority identities within an overarching category or rather stress the importance of shared unity against a background of diversity. The latter representation privileges commonality over minority identities rather than the other way around. An emphasis on minority identities is typical for West European multiculturalism, which is considered asymmetrical (only for minorities) and not concerned with developing commonality across ethnic boundaries (Goodhart, 2013; Joppke, 2004). That is one of the reasons why the Council of Europe (2008) considers multiculturalism inadequate as a policy approach and prefers the term interculturalism that emphasizes dialogue, dynamic identities and the promotion of unity in diversity (Cantle, 2012). We have focused on the importance of developing a sense of unity across cultural differences, and future research could examine other aspects of interculturalism (dialogue and dynamic identities) and how they relate to political orientation, education and justifying beliefs. Future research could also examine whether laypeople understand multiculturalism and interculturalism as separate ideological frameworks (Meer \& Modood, 2012).

A second limitation is that no causal inferences can be made because the three studies were cross-sectional. We used relatively large national samples that are crucial for adequately investigating the roles of political orientation and education: the politically right and left and lower and higher educated have to be sufficiently represented. Furthermore, the model tested was theoretically derived and although, for example, autochthony beliefs could inform political orientations, it is reasonable to assume that political orientation and education imply a set of relatively stable beliefs (Jost et al., 2003b). In addition, it seems likely that relatively general ideological constructs, such as autochthony, deprovincialization, conformity and social dominance, predict people's view on how to accommodate cultural diversity in society. Further, experimental research has demonstrated that autochthony beliefs influence evaluations of minority out-groups (e.g., Smeekes, Verkuyten, \& Martinovic, 2015). Yet, our research is cross-sectional, and it is possible that, for example, actual, everyday experiences with diversity lead to a less parochial world view and less emphasis on primo-occupancy. Thus, there might be mutual influences, and what the similar findings in our three studies then show are important and plausible directions of influence. Future research using longitudinal and experimental designs should examine these processes further.

\section{Conclusions}

In the European context, multiculturalism has increasingly been challenged and criticized and an emphasis on unity in diversity (i.e., interculturalism) has been proposed as a more adequate framework for dealing with diversity. We have demonstrated that political orientation and also education are simultaneously important for understanding why people endorse common national belonging and that autochthony beliefs (for native majority) and deprovincialization (for majority and minority) play independent mediating roles in these relations. Political orientation and level of education represent two main societal cleavages in most Western societies, making it important for social psychology to study their meaning and impact. The current findings indicate that these cleavages also exist in relation to the accommodation and management of cultural diversity. This means that it will not be easy to develop widespread support for a non-assimilationist common national identity that emphasizes unity in diversity. For this, it is important to understand the processes through which 
political orientation and also education have an impact on the support for unity in diversity. The current findings indicate that not only more general ideological beliefs (conformity and social dominance) are important but also beliefs about the nature of the national identity and culture. Political orientation and also education are related to a parochial or rather more deprovincialized cultural world view and to autochthony as an ideology that assigns ownership and entitlements to primooccupants of a country. This indicates that the development of widespread majority group support for unity in diversity requires a reappraisal of the in-group culture and also a notion of collective ownership that is based, for example, on making a contribution to society rather than on being there first.

\section{References}

Barone, C., Lucchini, M., \& Sarti, S. (2007). Class and political preferences in Europe: A multilevel analysis of trends over time. European Sociological Review, 23, 373-392.

Bekhuis, H., Lubbers, M., \& Verkuyten, M. (2014). Globalization and nationalist attitudes in 52 countries, between 1981 and 2009. International Journal of Public Opinion Research, 26, 487-500.

Bobo, L., \& Licari, F. C. (1989). Education and political tolerance. Testing the effects of cognitive sophistication and target group affect. Public Opinion Quarterly, 53, 285-308.

Bovens, M., Dekker, P., \& Tienteijer, W. (Eds) (2014). Gescheiden werelden? Een verkenning van sociaal-culturele tegenstellingen in Nederland (Separate worlds? An examination of socio-cultural cleavages in the Netherlands). The Hague, The Netherlands: WRR/SCP.

Cantle, T. (2012). Interculturalism: The new era of cohesion and diversity. London, UK: Palgrave-Macmillan.

Ceuppens, B. (2011). From 'the Europe of the regions' to 'the European Champion League': The electoral appeal of populist autochthony discourses in Flanders. Social Anthropology, 19, 159-174.

Chambers, J. R., Schlenker, B. R., \& Collison, B. (2012). Ideology and prejudice: The role of value conflicts. Psychological Science, 24, 140-149.

Coenders, M., \& Scheepers, P. (2003). The effect of education on nationalism and ethnic exclusionism: An international comparison. Political Psychology, 24, 313-343.

Cornelis, I., \& Van Hiel, A. (2014). Extreme-right voting in Western Europe: The role of social-cultural and antiegalitarian attitudes. Political Psychology. Advance online publication. http://dx.doi.org/10.1111/pops.12187

Council of Europe (2008). White paper on intercultural dialogue: living together as equals in dignity. Strasbourg, France: Council of Europe.

Dovidio, J. F., Gaertner, S. L., \& Saguy, T. (2009). Commonality and the complexity of 'we': Social attitudes and social change. Personality and Social Psychology Review, 13, 3-20. http://dx.doi.org/10.1177/1088868308326751

Duckitt, J. (2001). A dual-process cognitive-motivational theory of ideology and prejudice. In M. P. Zanna (Ed.), Advances in experimental social psychology (Vol. 33, pp. 41113). San Diego, CA: Academic Press.

Duckitt, J., Wagner, C., du Plessis, I., \& Birum, I. (2002). The psychological bases of ideology and prejudice: Testing a dual process model. Journal of Personality and Social Psychology, 83, 75-93.

Gaasholt, O., \& Togeby, L. (1995). Interethnic tolerance, education and political orientation: Evidence from Denmark. Political Behavior, 17, 265-285.

Gaertner, S. L., \& Dovidio, J. F. (2000). Reducing intergroup bias: The common ingroup identity model. New York, NY: Routledge.

Gaertner, S. L., Rust, M. C., Dovidio, J. F., Bachman, B. A., \& Anastasio, P. A. (1996). The contact hypothesis: The role of a common in-group identity on reducing intergroup bias among majority and minority group members. In J. L. Nye, \& A. M. Brower (Eds.), What's social about social cognition? (pp. 230-260). Newbury Park, CA: Sage.

Gans, C. (2001). Historical rights: The evaluation of nationalist claims to sovereignty. Political Theory, 29, 58-79.

Geschiere, P. (2009). The perils of belonging: Autochthony, citizenship, and exclusion in Africa and Europe. Chicago, IL: University of Chicago Press.

Goodhart, G. (2013). The British dream: Successes and failures of post-war immigration. London, UK: Atlantic Books.

Henrich, J., Heine, S. J., \& Norenzayan, A. (2010). The weirdest people in the world? Behavioral and Brain Sciences, 33, 61-135. http://dx.doi.org/10.1017/S0140525X0999152X

Henry, P. J. (2008). College sophomores in the laboratory redux: influences of a narrow data base on social psychology's view of the nature of prejudice. Psychological Inquiry, 19, 49-71. http://dx.doi.org/10.1080/10478400802049936.

Himmelweit, H. T., \& Gaskell, G. (Eds.). (1990). Societal psychology: Implications and scope. London, UK: Sage.

Hindriks, P., Verkuyten, M., \& Coenders, M. (2014). Dimensions of social dominance orientation: The roles of legitimizing myths and national identification. European Journal of Personality, 28, 538-549.

Ho, A. K., Sidanius, J., Pratto, F., Levin, S., Thomsen, L., Kteily, N., \& Sheehy-Skeffington, J. (2012). Social dominance orientation: Revisiting the structure and function of a variable predicting social and political attitudes. Personality and Social Psychology Bulletin, 38, 583-606.

Hodson, G., \& Hewstone, M. (Eds.). (2012). Advances in intergroup contact. Hove, UK: Psychology Press.

Hogg, M. A. (2007). Uncertainty-identity theory. Advances in Experimental Social Psychology, 39, 69-126.

Joppke, C. (2004). The retreat of multiculturalism in the liberal state: Theory and policy. British Journal of Sociology, 55, 237-257.

Jost, J. T. (2006). The end of the end of ideology. American Psychologist, 61, 651-670.

Jost, J. T., Glaser, J., Kruglanski, A. W., \& Sulloway, F. J. (2003a). Exceptions that prove the rule: Using a theory of motivated social cognition to account for ideological incongruities and political anomalies. Psychological Bulletin, $129,383-393$.

Jost, J. T., Glaser, J., Kruglanski, A. W., \& Sulloway, F. J. (2003b). Political conservatism as motivated social cognition. Psychological Bulletin, 129, 339-375.

Kundnani, A. (2007). Integrationism: The politics of antiMuslim racism. Race and Class, 48, 24-44. http://dx.doi. org/10.1177/0306396807077069

Kunst, J. R., Thomsen, L., Sam, D. L., \& Berry, J. W. (2015). We are in this together: Common group identity predicts majority members' active acculturation efforts to integrate 
immigrants. Personality and Social Psychology Bulletin, 41, 1438-1453. http://dx.doi.org/10.1177/0146167215599349.

Layman, G. C., Carsey, T. M., \& Horowitz, J. M. (2006). Party polarization in American politics: Characteristics, causes and consequences. Annual Review of Political Science, 9, 83-110.

Martinovic, B., \& Verkuyten, M. (2013). 'We were here first, so we determine the rules of the game': Autochthony and prejudice toward outgroups. European Journal of Social Psychology, 43, 637-647.

Meer, N., \& Modood, T. (2012). How does interculturalism contrast with multiculturalism? Journal of Intercultural Studies, 33, 175-196.

Meeusen, C., De Vroome, T., \& Hooghe, M. (2013). How does education have an impact on ethnocentrism: A structural equation analysis of cognitive, occupational status and network mechanisms. International Journal of Intercultural Relations, 37, 502-522.

Murphy, A. B. (1990). Historical justification for territorial claims. Annals of the Association of American Geographers, 80, 531-548.

Ohlander, J., Batalova, J., \& Treas, J. (2005). Explaining educational influences on attitudes toward homosexual relations. Social Science Research, 34, 781-799.

Ostapczuk, M., Musch, J., \& Moshagen, M. (2009). A randomized-response investigation of the education effect in attitudes towards foreigners. European Journal of Social Psychology, 39, 586-611.

Parekh, B. (2000). Rethinking multiculturalism: Cultural diversity and political theory. London, UK: MacMillan.

Pettigrew, T. F. (1997). Generalized intergroup contact effects on prejudice. Personality and Social Psychology Bulletin, 23, 173-185.

Pettigrew, T. F., \& Tropp, L. (2011). When groups meet: The dynamics of intergroup contact. New York, NY: Psychology Press.

Preacher, K. J., \& Hayes, A. F. (2008). Asymptotic and resampling strategies for assessing and comparing indirect effects in multiple mediator models. Behavior Research Methods, 40, 879-891.

Rattansi, A. (2011). Multiculturalism: A short introduction. Oxford, UK: Oxford University Press.

Scheepers, P., Gijsberts, M., \& Coenders, M. (2002). Ethnic exclusionism in European countries. Public opposition to civil rights for legal migrants as a response to perceived ethnic threat. European Sociological Review, 18, 17-34.

Sears, D. O., \& Henry, P. J. (2003). The origins of symbolic racism. Journal of Personality and Social Psychology, 85, 259-275.

Shaefer, R. T. (1996). Education and prejudice: Unraveling the relationship. The Sociological Quarterly, 37, 1-16.

Sidanius, J., \& Pratto, F. (1999). Social dominance: An intergroup theory of social hierarchy and oppression. Cambridge, UK: Cambridge University Press.

Sidanius, J., Pratto, F., \& Bobo, L. (1996). Racism, conservatism, affirmative action, and intellectual sophistication: A matter of principle or group dominance? Journal of Personality and Social Psychology, 70, 476-490.

Simons, D. J. (2014). The value of direct replication. Perspectives on Psychological Science, 9, 76-80. http://dx.doi.org/ $10.1177 / 1745691613514755$.

Smeekes, A., Verkuyten, M., \& Martinovic, B. (2015). Longing for the country's good old days: National nostalgia, autochthony beliefs, and opposition to Muslim expressive rights. British Journal of Social Psychology, 54, 561-580.

Taylor, C. (2012). Interculturalism or multiculturalism? Philosophy and Social Criticism, 38, 413-423.

Thorisdottir, H., Jost, J. T., Liviatan, I., \& Shrout, P. E. (2007). Psychological needs and values underlying left-right political orientation: Cross-national evidence from Eastern and Western Europe. Public Opinion Quarterly, 72, 175-203.

Toft, M. D. (2014). Territory and war. Journal of Peace Research, $51,185-198$.

Uberoi, V. (2008). Do policies of multiculturalism change national identities? The Political Quarterly, 79, 404-417. http://dx.doi.org/10.1111/j.1467-923X.2008.00942.x.

Valdesolo, P., \& Graham, J. (2016). Social psychology of political polarization. London, UK: Routledge.

Van Prooijen, J.-W., Krouwel, A. P. M., Noiten, M., \& Eendebak, L. (2015). Fear among the extremes: How political ideology predicts negative emotions and outgroup derogation. Personality and Social Psychology Bulletin, 41, 485-497.

Verkuyten, M. (2014). Identity and cultural diversity: What social psychology can teach us. Hove, UK: Routledge.

Verkuyten, M., \& Martinovic, B. (2015). Behind the ethniccivic distinction: Public attitudes towards immigrants' political rights in the Netherlands. Social Science Research, $53,43-44$.

Verkuyten, M., Martinovic, B., \& Smeekes, A. (2014). The multicultural jigsaw puzzle: Category indispensability and the acceptance of immigrants' cultural rights. Personality and Social Psychology Bulletin, 40, 1480-1493.

Verkuyten, M., Thijs, J., \& Bekhuis, H. (2010). Intergroup contact and ingroup reappraisal: Examining the deprovincialization thesis. Social Psychology Quarterly, 73, 398-416.

Vogt, W. P. (1997). Tolerance and education: Learning to live with diversity and difference. London, UK: Sage.

Wagner, U., \& Zick, A. (1995). The relation of formal education to ethnic prejudice: Its reliability, validity and explanation. European Journal of Social Psychology, 25, 41-56.

Wenzel, M., Mummendey, A., \& Waldzus, S. (2007). Superordinate identities and intergroup conflict: The ingroup projection model. European Review of Social Psychology, 18, 331-372.

Wetherell, G. A., Brandt, M. J., \& Reyna, C. (2013). Discrimination across the ideological divide: The role of value violations and abstract values in discrimination by liberals and conservatives. Social Psychological and Personality Science, 4, 658-667. 